(2)

OPEN ACCESS

\title{
Low-dose thrombolysis for submassive pulmonary embolism
}

\author{
Emine Serap Yilmaz (D) , ${ }^{1}$ Oğuz Uzun (D) ${ }^{2}$
}

\begin{abstract}
${ }^{1}$ Pulmonary Medicine, Ordu University Faculty of Medicine, Training and Research Hospital, Ordu, Turkey

${ }^{2}$ Pulmonary Medicine, Ondokuz Mayis University Faculty of Medicine, Samsun, Turkey
\end{abstract}

\section{Correspondence to} Dr Emine Serap Yilmaz, Training and Research Hospital Pulmonary Medicine, Ordu University Faculty of Medicine, Ordu Altınordu, Turkey; serapenderyilmaz@gmail. com

Accepted 18 May 2021

Check for updates

(C) American Federation for Medical Research 2021. Re-use permitted under CC BY-NC. No commercial re-use. Published by BMJ.

\begin{tabular}{|l|}
\hline To cite: Yilmaz ES, \\
Uzun O. I Investig Med \\
Epub ahead of print: \\
[please include Day Month \\
Year]. doi:10.1136/jim- \\
2021-001816 \\
\hline
\end{tabular}

\begin{abstract}
The role of thrombolysis in submassive pulmonary embolism (PE) is controversial due to the high risk of hemorrhage. This study aimed to evaluate the role of half-dose tissue-type plasminogen activator (rt-PA) in preventing death/hemodynamic decompensation in submassive (intermediate-risk) PE without increasing the risk of bleeding. In a prospective, non-randomized, open-label, singlecenter trial, we compared $50 \mathrm{mg}$ rt-PA plus low molecular weight heparin (LMWH) with LMWH in submassive (intermediate-risk) PE. Eligible cases had confirmed pulmonary hypertension on echocardiography, and/or right ventricular cavity expansion and/or interventricular septal deviation on echocardiography, and/or right to left ventricular ratio equal to or greater than $0.9 \mathrm{~mm}$ on $\mathrm{CT}$ angiography. The primary outcome was death or hemodynamic decompensation within 7 and 30 days after treatment was given. The primary safety outcome was major extracranial bleeding or hemorrhagic stroke within 7 days. Seventy-six patients were included in the study. Total death/ hemodynamic decompensation in the first 7 and 30 days was significantly less in the half-dose rtPA group than in the LMWH group ( $p=0.028$ and $p=0.009$, respectively). No significant differences were found between the two groups in terms of recurrent embolism and pulmonary hypertension at 6-month follow-up ( $p=1.000$ and $p=0.778)$. There was no intracranial hemorrhage in any of the patients. There were no statistically significant differences between the two groups in terms of major or minor bleeding complications. This trial showed half-dose rt-PA treatment in submassive (intermediate-risk) PE prevented death/hemodynamic decompensation in the first 7-day and 30-day period compared with LMWH treatment without increasing the risk of bleeding.
\end{abstract}

\section{INTRODUCTION}

Venous thromboembolism (VTE) is the third most common acute cardiovascular disease after myocardial infarction and stroke. ${ }^{1}$ Risk stratification according to massive (high-risk), submassive (intermediate-risk) and non-massive (low-risk) clinical definitions is based on clinical presentation and markers of myocardial dysfunction and/or injury. The mortality rate is

\section{Significance of this study}

What is already known about this subject?

- Patients in the submassive group (intermediate-risk) are in the most controversial group for thrombolytic therapy.

- Although thrombolytic drugs have been used as a life-saving agent in massive pulmonary embolism (PE) (high-risk group) with persistent hypotension, they have not been used in the non-massive group (low-risk) due to the high frequency of fatal intracranial hemorrhage.

- A higher incidence of stroke and major nonintracranial bleeding in the thrombolytic group was observed in the PEITHO trial, which intended to solve the controversial issue in intermediate-risk pulmonary embolism cases.

- Unfortunately the question whether or not to lyse in submassive PE was not solved in the PEITHO trial.

What are the new findings?

- The main objectives of treating patients with pulmonary thromboembolism are to prevent mortality without causing bleeding in acute setting and to prevent recurrence and development of pulmonary hypertension in the long term.

- The present study aimed to solve the same question (whether or not to lyse in submassive $\mathrm{PE})$, comparing half-dose thrombolytics with low molecular weight heparin anticoagulation only.

- This study demonstrated that half-dose tissue-type plasminogen activator (rt-PA) prevents death/hemodynamic decompensation in the first 7 and 30 days in patients with submassive PE without increasing hemorrhagic complications.

How might these results change the focus of research or clinical practice?

- Half-dose thrombolytic therapy in patients diagnosed with submassive (intermediate-risk) PE significantly reduced death/hemodynamic decompensation in the first 7 and 30 days compared with anticoagulant therapy.

nearly 58\% among hemodynamically unstable massive patients and about $15 \%$ among hemodynamically stable patients. ${ }^{23}$ 


\section{Significance of this study}

- There was no significant difference in both treatment groups in terms of bleeding complications, and none of the patients had intracranial hemorrhage.

- Our results support the use of low-dose rt-PA in normotensive PE cases with right ventricular dysfunction diagnosed on echocardiography and/or a high right ventricle to left ventricle ratio on CT pulmonary angiography, especially in cases presenting with high pulmonary arterial CT obstruction index rate and/or pulmonary artery systolic pressure on echocardiography.

Patients in the submassive group (intermediate-risk) are in the most controversial group for thrombolytic therapy. Although thrombolytic drugs have been used as a lifesaving agent in massive pulmonary embolism (PE) (highrisk group) with persistent hypotension, ${ }^{45}$ they have not been used in the non-massive group (low-risk) due to the high frequency of fatal intracranial hemorrhage (ICH). ${ }^{6}$ Although submassive PE is not as much as massive PE, it indicates a high-risk patient group. This group of patients need particular interest as there may have an in-hospital mortality of up to $30 \% .{ }^{78} \mathrm{~A}$ higher incidence of stroke and major non-intracranial bleeding in the thrombolytic group was observed in the Pulmonary Embolism Thrombolysis (PEITHO) trial, ${ }^{9}$ which intended to solve the controversial issue in intermediate-risk pulmonary emboli cases. Unfortunately the question whether or not to lyse in submassive PE was not solved in this trial. The present study aimed to solve the same question (whether or not to lyse in submassive $\mathrm{PE})$, comparing half-dose thrombolysis with low molecular weight heparin (LMWH) anticoagulation only.

\section{METHODS}

\section{Study design}

A prospective, non-randomized, open-label, single-center trial was conducted between March 2015 and June 2018. We included 76 patients diagnosed with submassive pulmonary thromboembolism. The first patient included in the study was given half-dose tissue-type plasminogen activator (rt-PA) and the second patient was given LMWH treatment in turn. In the end, by keeping this order, 38 patients were taken into the half-dose rt-PA group and 38 patients into the LMWH group.

\section{Study population}

The inclusion criteria were as follows:

- Age 18 years or older.

- Acute PE objectively confirmed on CT pulmonary angiography (CTPA) and/or ventilation/perfusion scintigraphy, with onset of symptoms 15 days or less before enrollment.

- Confirmed pulmonary hypertension (pulmonary artery pressure over $40 \mathrm{~mm} \mathrm{Hg}$ ) on echocardiography, and/ or right ventricular cavity expansion (right ventricular end-diastolic diameter $>30 \mathrm{~mm}$ ) and/or interventricular septal deviation, or right ventricular free wall hypokinesis and/or right to left ventricular ratio equal to or greater than $0.9 \mathrm{~mm}$ on CTPA.
- Absence of systemic hypotension (systolic blood pressure $<90 \mathrm{~mm} \mathrm{Hg}$ ) or shock condition.

The exclusion criteria were as follows:

- Hemodynamic decompensation or shock status.

- Risk of known bleeding.

- Ischemic stroke $<3$ months.

- Presence of uncontrolled hypertension (systolic $>180$ $\mathrm{mm} \mathrm{Hg}$ and/or diastolic $>110 \mathrm{~mm} \mathrm{Hg}$ ).

- Known hypersensitivity to thrombolytic therapy or LMWH.

- Known coagulation defect (including treatment with vitamin $\mathrm{K}$ antagonist or platelet count below 100 000/ $\mathrm{mm}^{3}$ ).

- Recent major surgery ( $<1$ week).

\section{Study treatment regimens}

For the half-dose thrombolysis group, $50 \mathrm{mg}$ rt-PA was added to $100 \mathrm{~mL}$ physiological saline, which was infused using an infusion pump for 2 hours. Subsequent to the completion of the thrombolytic therapy, patients' activated partial thromboplastin time was checked every 4 hours. Following recovery to less than twofold the basic control value, enoxaparin $(1 \mathrm{mg} / \mathrm{kg})$ was infused by subcutaneous injection every 12 hours. For the anticoagulation group, enoxaparin $(1 \mathrm{mg} / \mathrm{kg})$ was infused by subcutaneous injection every 12 hours. Warfarin was started simultaneously with enoxaparin in the half-dose rt-PA group and 1-2 days later than enoxaparin in the LMWH group. Heparin can be discontinued after a minimum of 5 days provided that the international normalized ratio has been 2.0 or higher for at least 24 hours. The treatment continued for at least 3 months.

\section{Efficacy results}

The primary efficacy outcome of this study was death from any cause and death/hemodynamic decompensation within 7 and 30 days after treatment was given. The secondary outcomes included recurrence of PE and pulmonary hypertension in the 6-month period. Safety outcomes were defined as ischemic or hemorrhagic stroke within 7 days after treatment was given and extracranial major bleeding within 7 days according to the International Society on Thrombosis and Haemostasis definition. ${ }^{10}$

Hemodynamic decompensation (or collapse) was defined as the need for cardiopulmonary resuscitation; or systolic blood pressure $<90 \mathrm{~mm} \mathrm{Hg}$ for at least $15 \mathrm{~min}$ or drop of systolic blood pressure by at least $40 \mathrm{~mm} \mathrm{Hg}$ for at least 15 min, with signs of end-organ hypoperfusion (cold extremities or low urinary output $<30 \mathrm{~mL} /$ hour or mental confusion); or need for catecholamine administration to maintain adequate organ perfusion and a systolic blood pressure of $>90 \mathrm{~mm} \mathrm{Hg}$.

\section{Evaluation parameters}

In this prospective study, patients' sociodemographic characteristics such as age, gender, symptoms, risk factors, vital signs, electrocardiography findings, and blood gases, D-dimer and cardiac biomarker values (troponin) were evaluated. The cut-off value for D-dimer by ELISA method was taken as $500 \mu \mathrm{g} / \mathrm{L}$ for those aged below 50 and age $\times 10 \mu \mathrm{g} / \mathrm{L}$ 
for those aged over $50 .{ }^{11}$ The cut-off value for troponin I was accepted at $0.110 \mu \mathrm{g} / \mathrm{mL}^{12}$

The Pulmonary Embolism Severity Index, which is a pretreatment risk assessment test, was calculated and intermediate-low and intermediate-high risk groups were determined. Chest radiography, ventilation/perfusion scintigraphy, lower extremity compression ultrasonography, echocardiography and CTPA findings were noted at the time of diagnosis. CTPA showed partial or complete occlusion of the vessel by localization of the filling defect in the lobar and segmental branches of the main, right and left pulmonary arteries. Pulmonary arterial CT obstruction index (PACTOI) and pulmonary arterial CT obstruction index rate (PACTOIR) were calculated using these data. ${ }^{13}$ By studying related articles, we calculated the PACTOI and PACTOIR by ourselves:

PACTOI $=\mathrm{n} \times \mathrm{d}$

PACTOIR $=$ PACTOI $\times 100 /$ maximal total score $(40)$

where $\mathrm{n}$ is the number of segmental branches arising distally (1-20) and $\mathrm{d}$ is the degree of obstruction: 0 (none), 1 (partial) and 2 (complete).

Control CTPA and echocardiography at 6 months of treatment were performed to examine residual and/or chronic organized thrombus in pulmonary arteries and pulmonary hypertension. In the simplified Bernoulli equation for predicted pulmonary artery systolic pressure (PASP) measurement, tricuspid regurgitation jet flow rate and right atrial pressure were used and were calculated using the following formula:

Systolic PASP $=[4 \times($ tricuspid regurgitation flow rate $\left.)^{2}\right]+$ right atrial pressure.

\section{Statistical analysis}

The data obtained from the study were coded and analyzed in SPSS V.15.0 package program. While data were evaluated, continuous variables were expressed as mean $\pm S D$, median and lowest-highest values, and census data were expressed in numbers and percentages. In statistical analysis, conformity of continuous variables to normal distribution was evaluated with 'Kolmogorov-Smirnov Test'. When the continuous variables obtained in the study did not comply with the normal distribution, they were given the highest and lowest values with the median values, instead of mean and SD. The Mann-Whitney U test was used in the groups that did not comply with the normal distribution in the comparisons between the arithmetic means of the continuous variables. Pearson's $\chi^{2}$ test was used to compare categorical data. A p value of 0.05 was accepted as the statistical significance limit.

\section{RESULTS}

\section{Baseline characteristics}

Seventy-six patients were included in the study. The mean age of the patients who received half-dose thrombolysis was 69 years, which was comparable with the age of those in the LMWH group, which was 63 years. Of the patients, 41 (54\%) were female and 35 (46\%) were male. Patients over the age of 75 constituted $33 \%(n=25)$ of all patients. Chronic pulmonary disease was present in $10(13 \%)$ patients and chronic heart disease in 15 (20\%). Patients with body
Table 1 Baseline clinical characteristics of the study patients in both groups

\begin{tabular}{|c|c|c|c|}
\hline & $\begin{array}{l}\text { Half-dose rt-PA } \\
(\mathrm{n}=38)\end{array}$ & LMWH $(n=38)$ & $P$ value \\
\hline Age & $69 \pm 14$ & $63 \pm 16$ & 0.085 \\
\hline Sex, n (\%) & & & 0.107 \\
\hline Male & $21(55)$ & $14(37)$ & \\
\hline Female & $17(45)$ & $24(64)$ & \\
\hline $\mathrm{SBP}(\mathrm{mm} \mathrm{Hg})$ & $126 \pm 23$ & $124 \pm 17$ & 0.9 \\
\hline $\mathrm{DBP}(\mathrm{mm} \mathrm{Hg})$ & $77 \pm 13$ & $80 \pm 11$ & 0.758 \\
\hline $\begin{array}{l}\text { Respiratory rate (per } \\
\text { minute) }\end{array}$ & $26 \pm 2.9$ & $24 \pm 3.2$ & 0.006 \\
\hline $\begin{array}{l}\text { Oxygen saturation (in } \\
\text { room air) }\end{array}$ & $88 \pm 4.8$ & $91 \pm 4.8$ & 0.019 \\
\hline $\mathrm{PaO}_{2}(\mathrm{~mm} \mathrm{Hg})$ & $62 \pm 5.8$ & $70 \pm 6.2$ & 0.032 \\
\hline Troponin (g/mL) & $2.60 \pm 0.4$ & $2.48 \pm 0.4$ & 0.685 \\
\hline \multicolumn{4}{|l|}{ Risk factors, n (\%) } \\
\hline Immobility & $27(71)$ & $22(60)$ & 0.338 \\
\hline Malignancy & $8(21)$ & 7 (18) & 1.000 \\
\hline DVT history & $6(16)$ & $9(24)$ & 0.564 \\
\hline PE history & $4(10)$ & $3(8)$ & 1.000 \\
\hline Obesity $\left(\mathrm{BMI}>30 \mathrm{~kg} / \mathrm{m}^{2}\right)$ & $10(26)$ & $15(40)$ & 0.329 \\
\hline $\begin{array}{l}\text { Surgery (in the last } 45 \\
\text { days) }\end{array}$ & $8(21)$ & $10(26)$ & 0.787 \\
\hline $\begin{array}{l}\text { Trauma (in the last } 45 \\
\text { days) }\end{array}$ & $3(8)$ & $2(5)$ & 1.000 \\
\hline Hormone therapy & $1(3)$ & $4(10)$ & 0.358 \\
\hline \multicolumn{4}{|c|}{ Presenting symptoms, n (\%) } \\
\hline Dyspnea & $37(97)$ & $36(94)$ & 1.000 \\
\hline Chest pain & $22(60)$ & $26(68)$ & 0.476 \\
\hline Cough & $3(8)$ & $6(16)$ & 0.480 \\
\hline Hemoptysis & $3(8)$ & $3(8)$ & 1.000 \\
\hline Syncope & $1(3)$ & $0(0)$ & 1 \\
\hline Duration of illness (days) & 1.60 & 1.86 & 0.07 \\
\hline
\end{tabular}

$\mathrm{BMI}$, body mass index; DBP, diastolic blood pressure; DVT, deep venous thrombosis; $\mathrm{LMWH}$, low molecular weight heparin; $\mathrm{PaO}_{2}$, partial pressure of arterial oxygen; rt-PA, tissue-type plasminogen activator; SBP, systolic blood pressure.

mass index over 30 constituted $33 \%$ of all patients. Twenty-one (28\%) patients were smokers.

Dyspnea was observed in almost all of the patients (96\%), while the second most frequent symptom was chest pain, which was present in $22(58 \%)$ patients in the half-dose thrombolytic group and $26(68 \%)$ in the LMWH group. As shown in table 1 , the presenting symptoms were similar between the two groups.

Immobilization was the most frequent risk factor for VTE, which was present in 49 (64\%) patients of both groups. Fifteen $(20 \%)$ patients had cancer. The initial presentation of three lung cancer cases was PE. Fifteen (20\%) patients had a history of deep venous thrombosis and seven (9\%) had a history of PE (table 1). Oral contraceptive drugs, hormone replacement treatments during the menopause period and hormonal drugs used for malignancies were evaluated as hormone therapy.

There was no statistical difference between the two groups in terms of ECG and chest radiography findings.

CTPA was used as the main diagnostic method in this study. However, pulmonary thromboembolism in three 


\begin{tabular}{|c|c|c|c|}
\hline & $\begin{array}{l}\text { Half-dose rt-PA } \\
\mathrm{n}=38(\%)\end{array}$ & $\begin{array}{l}\text { LMWH } \\
\mathrm{n}=38(\%)\end{array}$ & $\begin{array}{l}P \\
\text { value }\end{array}$ \\
\hline PACTOIR & $75(12.5-100)$ & $75(25-100)$ & 0.505 \\
\hline Right to left ventricular ratio & $1.2(1.0-1.7)$ & $1.2(0.9-2.0)$ & 0.888 \\
\hline Pleural effusion & $11(29.7)$ & $5(13.9)$ & 0.176 \\
\hline Hampton hump & $9(24.3)$ & $3(8.3)$ & 0.127 \\
\hline Mosaic attenuation & $13(35.1)$ & $9(25.0)$ & 0.491 \\
\hline
\end{tabular}

LMWH, low molecular weight heparin; PACTOIR, pulmonary arterial CT obstruction index rate; rt-PA, tissue-type plasminogen activator.

patients for whom CTPA could not be performed due to the high creatinine level was diagnosed with high probability of ventilation/perfusion scintigraphy. The mean PACTOIR on CTPA was $75 \%$ in both groups. PACTOIR was $100 \%$ in 10 patients in the half-dose rt-PA group and in 8 patients in the LMWH group. PACTOIR was not significantly different between the two groups $(\mathrm{p}=0.505)$. The mean right to left ventricular ratio on CTPA was 1.2 in both groups. The CTPA findings are summarized in table 2 and the CTPA images of the three sample cases are shown in figures 1-3.

Echocardiography revealed interventricular septal shift in 69 patients (36 patients (95\%) in the half-dose rt-PA group and 33 patients $(87 \%)$ in the LMWH group). Pulmonary arterial pressure was found to be $55 \mathrm{~mm} \mathrm{Hg}$ in both groups. Right ventricular enlargement or hypokinesis was observed in all patients in the half-dose rt-PA group (100\%) and 37 (97\%) patients in the LMWH group. There were no statistically significant differences between the two groups in terms of echocardiography findings at the time of diagnosis.

\section{Efficacy and safety outcomes}

Considering the success of treatment in both groups, it was observed that three patients died in 7 days and two patients died in 7-30 days. In the first 7 days, two (5\%) patients from the LMWH group and one (3\%) patient from the halfdose rt-PA group died. Patients in the LMWH group died of hemodynamic decompensation, while in the half-dose rt-PA group unexplained sudden death occurred. Two (5\%) patients from the LMWH group died between 7 and 30 days due to hemodynamic decompensation, while no death

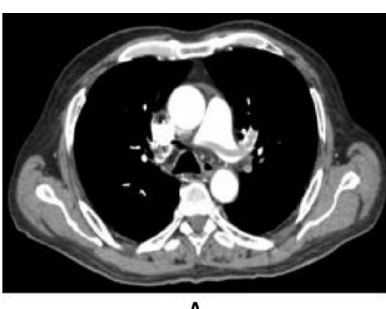

A

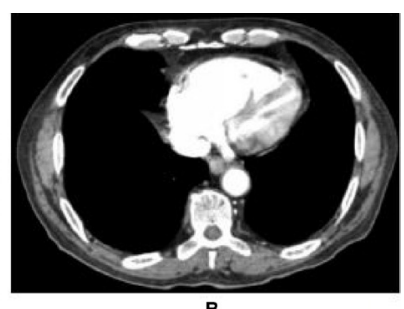

B
Figure 1 An adult malignant patient in the LMWH group had saddle emboli (A) and a right to left ventricular ratio of 2.7 (B) on $\mathrm{CT}$ pulmonary angiography. His blood pressure, respiratory rate, sPESI and PASP on echocardiography were $115 / 80 \mathrm{~mm} \mathrm{Hg}$, 32 per minute, 2 and $80 \mathrm{~mm} \mathrm{Hg}$, respectively. Unfortunately the patient was lost due to sudden hemodynamic decompensation at 8 hours of presentation. LMWH, low molecular weight heparin; PASP, pulmonary artery systolic pressure.

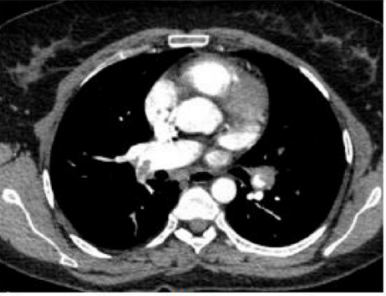

A

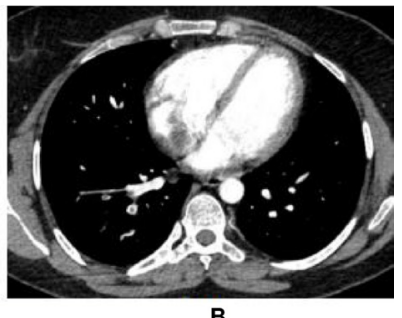

B
Figure 2 The second patient was from the LMWH group who had immobilization due to surgery and had total occlusion of bilateral pulmonary arteries $(A)$ with right to left ventricular ratio of 1.07 (B) on CT pulmonary angiography. Pulse rate, respiratory rate, blood pressure, sPESI and PASP on echocardiography at presentation were 121 per minute, 24 per minute, $120 / 70 \mathrm{~mm}$ $\mathrm{Hg}, 2$ and $65 \mathrm{~mm} \mathrm{Hg}$, respectively. Escalation half-dose rt-PA was administered due to hemodynamic decompensation and severe dyspnea. She had mild dyspnea at 6 months of treatment with PASP of $55 \mathrm{~mm} \mathrm{Hg}$ on echocardiography. LMWH, low molecular weight heparin; PASP, pulmonary artery systolic pressure; rt-PA, tissue-type plasminogen activator.

was observed in the half-dose rt-PA group. The efficacy and safety outcomes of the patients are shown in table 3 .

In the LMWH group, hemodynamic deterioration was observed in six $(15.8 \%)$ patients, requiring treatment for a half-dose escalation thrombolytic therapy. This clinical deterioration occurred in two patients on day 1 , in three patients on day 2 and in one patient on day 3 (mean $1.8 \pm 0.7$ days).

In the first 7 days, death/hemodynamic decompensation was seen in one $(3 \%)$ patient in the half-dose rt-PA group

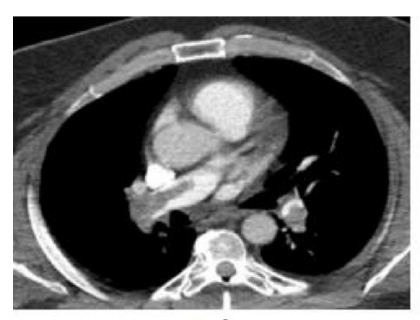

A

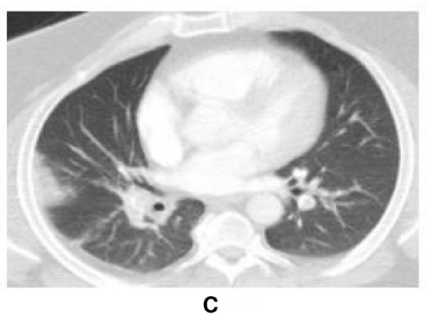

C

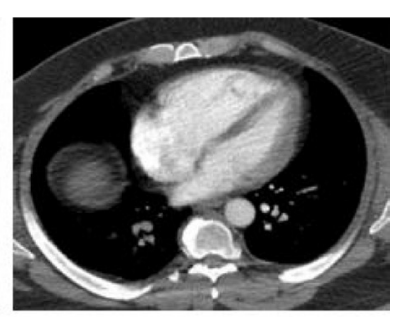

B
Figure 3 The third patient was an obese man in his 40s with a pulse rate of 110 per minute, respiratory rate of 28 per minute, sPESI of 2 and PASP of $50 \mathrm{~mm} \mathrm{Hg}$ on echocardiography at presentation. Massive occlusion of pulmonary arteries with $75 \%$ PACTOIR (A), right to left ventricular ratio of 1.2 (B) and Hampton hump (C) were prominent on CT pulmonary angiography. He recovered without any complication with half-dose rt-PA therapy. PACTOIR, pulmonary arterial CT obstruction index rate; PASP, pulmonary artery systolic pressure; rt-PA, tissue-type plasminogen activator. 


\begin{tabular}{|c|c|c|c|}
\hline & $\begin{array}{l}\text { Half-dose rt-PA } \\
\mathrm{n}=38(\%)\end{array}$ & $\begin{array}{l}\text { LMWH } \\
\mathrm{n}=38(\%)\end{array}$ & $P$ value \\
\hline \multicolumn{4}{|l|}{ Primary composite outcomes within 30 days } \\
\hline Mortality in the first 7 days & $1(3)$ & $2(5)$ & 1.000 \\
\hline Mortality from 7 to 30 days & $0(0)$ & $2(5)$ & 0.493 \\
\hline Total mortality in the first 30 days & $1(3)$ & $4(10)$ & 0.358 \\
\hline Death/hemodynamic decompensation in the first 7 days & $1(3)$ & $8(21)$ & 0.028 \\
\hline Death/hemodynamic decompensation in the first 30 days & $1(3)$ & $10(26)$ & 0.009 \\
\hline \multicolumn{4}{|l|}{ Secondary endpoints ( 6 months after starting treatment) } \\
\hline Persistence of pulmonary artery filling defect on CTPA & $7(20)$ & $6(19)$ & 1.000 \\
\hline Mean PASP on echocardiography & $33 \pm 14$ & $33 \pm 19$ & 0.504 \\
\hline Pulmonary hypertension ( $\geq 40 \mathrm{~mm} \mathrm{Hg}$ on echocardiography) & $9(24)$ & $7(18)$ & 0.778 \\
\hline Recurrent embolism & $2(5)$ & $1(3)$ & 1.000 \\
\hline \multicolumn{4}{|l|}{ Safety outcome (bleeding) } \\
\hline Minor bleeding & $8(21)$ & $4(10)$ & 0.223 \\
\hline Major bleeding & $3(8)$ & $2(5)$ & 1.000 \\
\hline Age $>75(n=25)$ & $1(7)$ & $2(18)$ & 0.4 \\
\hline Age $<75(n=51)$ & $2(8)$ & 0 & \\
\hline
\end{tabular}

CTPA, CT pulmonary angiography; LMWH, low molecular weight heparin; PASP, pulmonary artery systolic pressure $>40 \mathrm{~mm} \mathrm{Hg}$; rt-PA, tissue-type plasminogen activator.

and in eight (21\%) patients in the LMWH group. There was a statistically significant difference between the two groups (OR $0.285,95 \% \mathrm{CI} 0.041$ to $0.332, \mathrm{p}=0.028$ ). In the first 30 days, $1(2.6 \%)$ patient in the half-dose rt-PA group and $10(26.3 \%)$ patients in the LMWH group had death/hemodynamic decompensation, and a statistically significant difference was found between the two groups $(p=0.009)$. There were no statistically significant differences in death/ hemodynamic decompensation between the two groups with regard to sex and age above 75 or younger.

Recurrent embolism was observed in three patients, one of whom in the LMWH group died during the 6-month follow-up. Sixteen (21\%) patients had pulmonary hypertension (PASP $>40 \mathrm{~mm} \mathrm{Hg}$ ) diagnosed on echocardiography at 6-month follow-up. Nine of these patients were from the half-dose rt-PA group and seven were from the LMWH group. In three of these seven patients in the LMWH group, control CTPA did not show a significant thrombus in the main pulmonary arteries, whereas in four patients thrombus persisted. In the half-dose rt-PA group, in four out of nine patients, there was no significant thrombus in the main pulmonary arteries in control CTPA, whereas in five patients the thrombus persisted. The 6-month control results of patients were not statistically different between the two groups, as shown in table 3.

\section{Safety outcomes}

During the first 7 days of follow-up, 12 patients had minor bleeding and 5 had major bleeding (16\% and 7\%, respectively). Six patients had subcutaneous hemorrhage, five had hemoptysis, three had genitourinary hemorrhage, two had gastrointestinal hemorrhage and one had epistaxis. None of the patients had ICH. Major bleeding was observed in two patients in the LMWH group and three patients in the half-dose thrombolytic group. There were no statistically significant differences between the two groups in terms of bleeding complications (table 3).
The distribution of major bleeding complications was also evaluated according to age and gender. Fourteen (37\%) patients in the half-dose rt-PA group and 11 (29\%) patients in the LMWH group were older than 75 years. In these patients, major bleeding was seen in one $(7 \%)$ patient in the half-dose rt-PA group and in two (18\%) patients in the LMWH group. In patients 75 years of age or younger, major hemorrhage was seen in two (8\%) patients in the half-dose rt-PA group and not in the LMWH group. There was no statistically significant difference between the two groups according to age and gender.

\section{DISCUSSION}

This study has demonstrated that half-dose rt-PA prevents death/hemodynamic decompensation in the first 7 and 30 days in patients with submassive PE without increasing hemorrhagic complications. To our knowledge, our study is the second prospective study comparing half-dose rt-PA and heparin. ${ }^{14}$ Two regimens in our study had similar effects on recurrent PE and development of pulmonary hypertension at 6 months. The main objectives of treating patients with pulmonary thromboembolism are to prevent mortality without causing bleeding in acute setting and to prevent recurrence and development of pulmonary hypertension in the long term. Our study achieved the first objective, with one death in the low-dose thrombolytic group compared with eight deaths/hemodynamic decompensations in the LMWH group. However, two regimens also showed similar effects on recurrence of thromboembolic event and development of pulmonary hypertension in the long term, consistent with previous studies. ${ }^{15} 16$

In massive pulmonary thromboembolism, half-dose $(50$ $\mathrm{mg} / 2$ hours) and full-dose (100 mg/2 hours) rt-PA regimens showed effectiveness, and in a study of side effects both regimens showed hemodynamic stability, where the half-dose regimen caused less bleeding complications in patients with body weight under $65 \mathrm{~kg}$. In both regimens 
it was put forward that recurrent pulmonary thromboembolism was not seen. Therefore, according to this study, when half-dose was compared with full-dose, in pulmonary thromboembolism, the similar effectiveness of the half-dose regimen provided more protection in terms of hemorrhage complications. ${ }^{15}$

In patients diagnosed with moderate-risk pulmonary thromboembolism, the reduced dose of thromboembolism treatment $(30 \mathrm{mg} / \mathrm{rt}-\mathrm{PA})$ and in the other study LMWH treatment compared, it was seen that when compared with LMWH group, there was an important decrease in pulmonary artery pressure and a healing in symptom intensity in rt-PA group. On their treatment on the 90th day, there were not any differences in terms of mortality, recurring VTE and major bleeding. However, in the rt-PA group, there were increased minor bleeding and reduced hemodynamic decompensation. As a conclusion, in this study, low-dose thromboembolism treatment could be advised as a protective and efficient treatment for patients diagnosed with moderate-risk pulmonary thromboembolism. ${ }^{16}$

\section{Thrombolytic efficacy}

Although the effectiveness of thrombolytics is indisputable in massive PE, ${ }^{5}$ management of submassive PE crosses the zone of equipoise, requiring the clinician to use clinical judgment. The risk of mortality is very high due to acute hemodynamic deterioration in the massive pulmonary thromboembolism. A study comparing thrombolytic therapy with heparin in patients with massive PE was terminated early because all patients in the heparin group died. ${ }^{5}$ Therefore, thrombolytic therapy was accepted as the standard treatment in this group of patients. ${ }^{4} 7$ Thrombolytic therapy leads to faster improvement in pulmonary obstruction, pulmonary arterial pressure, pulmonary vascular resistance and reduction in right ventricular failure in patients with massive PE, compared with unfractionated heparin (UFH) alone. ${ }^{5}{ }^{17-19}$ The earlier the treatment is started, the greater the benefit; however, thrombolytic treatment can still be used in patients who have had symptoms for 14 days. ${ }^{20}$ However, clinical guidelines do not recommend routine use of thrombolytics in submassive cases due to insufficient data; rescue thrombolytic therapy is instead recommended for patients with hemodynamic deterioration on anticoagulation treatment. ${ }^{4}$ However, this approach may be dangerous for at least some patients, as normotensive patients with PE may have elevated risk of early death if they present with right ventricular dysfunction or injury to the myocardium as a result of acute pressure overload. ${ }^{21} 22$

A number of randomized thrombolytic trials have been conducted showing the efficacy of thrombolytic therapy in submassive PE, but had controversial results in terms of bleeding, especially ICH. The Management Strategies and Prognosis of Pulmonary Embolism-3 (MAPPET-3) trial, ${ }^{23}$ conducted in 2002, evaluated the use of heparin plus 100 mg rt-PA in 118 patients and 138 receiving heparin plus placebo. The primary endpoint was met, with in-hospital death or clinical deterioration being significantly higher in the heparin group $(p=0.006)$ and the probability of 30 -day event-free survival was higher in the rt-PA plus heparin group $(\mathrm{p}=0.005)$. Bleeding rate was higher with rt-PA, but no fatal bleeding or ICH occurred in the rt-PA group. The randomized, double-blind PEITHO trial ${ }^{9}$ was a pivotal trial on acute PE which compared full-dose tenecteplase plus heparin with heparin plus placebo in 1006 patients with intermediate-risk PE. The study's primary outcome (allcause death or hemodynamic decompensation or collapse within 7 days of randomization) occurred in 13 of 506 (2.6\%) patients in the thrombolytic group compared with 28 of $449(5.6 \%)$ patients in the placebo group $(\mathrm{p}=0.02)$. ICH occurred in $10(2 \%)$ patients in the tenecteplase group and in only $1(0.2 \%)$ patient in the placebo group. Thus, this study has shown to prevent hemodynamic decompensation, which was consistent with our results, but at an increased risk of major hemorrhage and stroke, which was not observed in our study. The PEITHO trial has influenced guidelines, which do not endorse thrombolytic therapy for submassive (indermediate-risk) PE cases, although some other low-scale trials comparing full-dose thrombolytics and heparin did not show any difference in bleeding complication. ${ }^{182425}$

The disappointment with regard to the high ICH in the PEITHO trial led researchers in this field to conduct new research such as on using low-dose thrombolytics in this group of patients. Although rt-PA $100 \mathrm{mg} / 2$ hours has been recommended in the guidelines, the optimal regimens are less defined. In the 'real world' many clinicians choose to use lower doses of rt-PA due to fear of major bleeding, although no strong evidence exists. Lower doses of thrombolytics may be of particular interest in the elderly, small and pregnant patients, as well as those with relative contraindications. ${ }^{26}$ The currently used dose of rt-PA of $100 \mathrm{mg}$ is based on cardiology experience. ${ }^{27}$ However, if we consider that the lungs receive the entire cardiac output compared with the coronary arteries which receive only a fraction of it, the dose reduction of thrombolytics in the treatment of $\mathrm{PE}$ is a logical approach.

A randomized trial of 118 patients with either high-risk or intermediate-risk PE found that half-dose rt-PA resulted in fewer hemorrhagic complications than full-dose rt-PA and had similar effects on improvement in right ventricular diameter on echocardiography, lung perfusion defects and pulmonary artery obstruction. ${ }^{15}$

Subsequently, the prospective, randomized Moderate pulmonary embolism treated with thrombolysis (MOPETT) trial $^{14}$ compared low-dose rt-PA versus UFH or enoxaparin in 121 'moderate-risk' PE cases. Although all-cause mortality was similar in both groups, progression of pulmonary hypertension was statistically low in the lowdose thrombolytic group. In contrast to our study, pulmonary hypertension and recurrent PE developed in 9 (16\%) patients in the low-dose thrombolytic group and in 35 $(63 \%)$ in the heparin-only group during the 22 months of follow-up period of the MOPETT trial $(\mathrm{p}<0.001)$. No reported major or minor hemorrhage in both groups was especially criticized, which is thought to be very unusual in a study where 61 patients received systemic thrombolysis.

In a recent trial, further reduction of rt-PA dose to 30 mg has been compared with LMWH anticoagulation alone in 76 acute intermediate-risk PE. ${ }^{16}$ Even a reduced dose at this level has been shown to reduce PASP from $52 \mathrm{~mm}$ $\mathrm{Hg}$ to 34.8 in the low-dose group $(\mathrm{p}<0.01)$ and from 53.4 $\mathrm{mm} \mathrm{Hg}$ to $48.5 \mathrm{~mm} \mathrm{Hg}(\mathrm{p}=0.11)$ in the LMWH group. In terms of death, hemodynamic decompensation, recurrent 
PE and bleeding, $30 \mathrm{mg}$ rt-PA was non-inferior to the LMWH group, although hemodynamic decompensation was observed in none of the thrombolytic group compared with three cases in LMWH group.

According to the European Society of Cardiology/European Respiratory Society (ESC/ERS) guidelines, ${ }^{4}$ risk stratification is made by assessment of pulmonary embolism severity index (PESI) (or simplified pulmonary embolism severity index (sPESI)), right ventricular function on echocardiography and cardiac troponin testing after a diagnosis of PE has been confirmed. The intermediate-risk group is further divided into intermediate-high and intermediate-low risk groups. We have not observed any difference in death/hemodynamic decompensation according to intermediate-high and intermediate-low risk classification, with five in the intermediate-high and four in intermediate-low risk group of the total nine cases who have died or needed secondary thrombolysis.

Several studies have shown that low-dose thrombolytics decrease PASP in the first week of treatment. ${ }^{28}$ However, no difference in PASP on echocardiography was observed in low-dose thrombolytics compared with only heparin anticoagulation in the long term, except in the MOPETT trial. ${ }^{19}$ In the MOPETT study, ${ }^{14}$ PASP measurements on follow-up echocardiography at the 28th month were statistically higher in patients receiving anticoagulant-only therapy compared with half-dose rt-PA therapy. However, chronic thromboembolic pulmonary hypertension was not confirmed with right heart catheterization in any of the studies, although we have shown thrombotic occlusion of pulmonary arteries on CTPA in seven of nine patients who were in the half-dose rt-PA group and six of seven patients in the LMWH group at 6 months of treatment. Of the 16 patients who developed pulmonary hypertension in the long term, 11 were in intermediate-high and 5 intermediate-low risk group according to the ESC/ERS guidelines. ${ }^{4}$ Therefore, according to the results of our study, it should be kept in mind that hemodynamic decompensation and pulmonary hypertension may develop in both subgroups of intermediate-risk PE.

\section{Adverse events}

In the PEITHO study, ${ }^{9}$ extracranial and intracranial hemorrhage complications were significantly higher in the tenecteplase group compared with the placebo plus anticoagulant group. In another study comparing tenecteplase plus UFH and placebo plus UFH groups, there was no difference in major bleeding complications, whereas minor bleeding was more common in patients with tenecteplase. ${ }^{24}$ In the MAPPET-3 study, ${ }^{23}$ no significant difference was found in bleeding complications between rt-PA plus UFH and placebo plus UFH treatments. In the meta-analysis by Nakamura et al, ${ }^{29}$ the risk of major bleeding and $\mathrm{ICH}$ was found to be more common in the thrombolytic group, but was not statistically significant. In the MOPETT study, ${ }^{14}$ significant bleeding was not observed in any patients who received half-dose rt-PA plus anticoagulant and anticoagulant alone. In a systematic review by Zhang et al, ${ }^{28}$ it was observed that hemorrhagic complication reduced in the half-dose thrombolytic treatment compared with the full dose. In our study, there was no statistically significant difference between the half-dose rt-PA and the LMWH group in terms of bleeding complications $(p=0.254)$. No ICH was observed in our study. It has been shown that increasing age and comorbidities have been associated with a higher risk of bleeding complications in full-dose thrombolytic trials. ${ }^{9} 8$ Using half-dose rt-PA, we did not observe any difference in bleeding complications, with no ICH among patients who are over 75 years or younger.

Our findings, combined with those of another controlled trial of thrombolysis in submassive PE,${ }^{14}$ support the use of half-dose rt-PA instead of UFH/LMWH in preventing hemodynamic decompensation and use of secondary thrombolytic therapy.

\section{Study limitations}

We have several limitations to our study. We have a relatively small sample size due to the study being a singlecenter study, which prevented us from achieving more powerful results, especially with regard to death rate. Our study group included some differences in parameters such as respiratory rate, oxygen saturation and partial pressure of arterial oxygen $\left(\mathrm{PaO}_{2}\right)$, indicating that the low-dose thrombolytic group has more severe cases, although there was no difference between the groups in terms of risk classification. Although we think that this difference is coincidental, this unintentional situation increases the strength of the study as it seems the low-dose rt-PA group has relatively more severe cases. Another limitation was that the physicians responsible for treatment and follow-up of patients were not blinded to the treatment assignment. However, we defined very strict criteria for hemodynamic decompensation for further escalation of treatment to thrombolysis.

In conclusion, half-dose thrombolytic therapy in patients diagnosed with submassive (intermediate-risk) PE significantly reduced death/hemodynamic decompensation in the first 7 and 30 days compared with anticoagulant therapy. There was no significant difference in both treatment groups in terms of bleeding complications, and none of the patients had ICH. Our results support the use of low-dose rt-PA in normotensive $\mathrm{PE}$ cases with right ventricular dysfunction diagnosed on echocardiography and/or high right to left ventricular ratio on CTPA, especially in cases presenting with high PACTOIR and/or PASP on echocardiography.

Contributors Conception and design: ESY. Administrative support: both authors. Provision of the study materials or patients: both authors. Collection and assembly of data: ESY. Data analysis and interpretation: OU. Manuscript writing: both authors. Final approval of the manuscript: both authors. The authors are accountable for all aspects of the work in ensuring that questions related to the accuracy or integrity of any part of the work are appropriately investigated and resolved.

Funding The authors have not declared a specific grant for this research from any funding agency in the public, commercial or not-for-profit sectors.

Competing interests None declared.

Patient consent for publication Not required.

Ethics approval The trial was conducted in accordance with the Declaration of Helsinki (as revised in 2013). The study was reviewed and approved by the institutional ethics committee (2015/419 of OMU KAEK), and informed consent was taken from all individual subjects.

Provenance and peer review Not commissioned; externally peer reviewed. Data availability statement Data are available upon reasonable request. 
Open access This is an open access article distributed in accordance with the Creative Commons Attribution Non Commercial (CC BY-NC 4.0) license, which permits others to distribute, remix, adapt, build upon this work noncommercially, and license their derivative works on different terms, provided the original work is properly cited, an indication of whether changes were made, and the use is non-commercial. See: http://creativecommons.org/ licenses/by-nc/4.0/.

\section{ORCID iDs}

Emine Serap Yilmaz http://orcid.org/0000-0001-5308-4488

Oğuz Uzun http://orcid.org/0000-0002-0475-4198

\section{REFERENCES}

1 Carson JL, Kelley MA, Duff A, et al. The clinical course of pulmonary embolism. N Engl J Med Overseas Ed 1992;326:1240-5.

2 Goldhaber SZ, Visani L, De Rosa M. Acute pulmonary embolism: clinical outcomes in the International cooperative pulmonary embolism registry (ICOPER). Lancet 1999;353:1386-9.

3 Kucher N, Rossi E, DeRosa M. Massive pulmonary embolism. J Vasc Surg 2006;44:684-5.

4 Konstantinides SV, Meyer G, Becattini C, et al. 2019 ESC guidelines for the diagnosis and management of acute pulmonary embolism developed in collaboration with the European respiratory Society (ERS): the task force for the diagnosis and management of acute pulmonary embolism of the European Society of cardiology (ESC). Eur Respir J 2019;54:1901647.

5 Jerjes-Sanchez C, Ramírez-Rivera A, de Lourdes García M, et al. Streptokinase and heparin versus heparin alone in massive pulmonary embolism: a randomized controlled trial. J Thromb Thrombolysis 1995;2:227-9.

6 Dalla-Volta S, Palla A, Santolicandro A, et al. PAIMS 2: alteplase combined with heparin versus heparin in the treatment of acute pulmonary embolism. plasminogen activator Italian multicenter study 2. J Am Coll Cardiol 1992;20:520-6.

7 Kearon C, AkI EA, Ornelas J, et al. Antithrombotic therapy for VTe disease: chest guideline and expert panel report. Chest 2016;149:315-52.

8 Kucher N, Goldhaber SZ. Management of massive pulmonary embolism. Circulation 2005;112:e28-32.

9 Meyer G, Vicaut E, Danays T, et al. Fibrinolysis for patients with intermediaterisk pulmonary embolism. N Engl J Med 2014;370:1402-11.

10 Schulman S, Kearon C, the SUBCOMMITTEE ON CONTROL OF ANTICOAGULATION OF THE SCIENTIFIC AND STANDARDIZATION COMMITTEE OF THE INTERNATIONAL SOCIETY ON THROMBOSIS AND HAEMOSTASIS. Definition of major bleeding in clinical investigations of antihemostatic medicinal products in non-surgical patients. J Thromb Haemost 2005:3:692-4

11 Douma RA, le Gal G, Söhne M, et al. Potential of an age adjusted D-dimer cut-off value to improve the exclusion of pulmonary embolism in older patients: a retrospective analysis of three large cohorts. Br Med J 2010;340:1475.

12 Becattini C, Vedovati MC, Agnelli G. Prognostic value of troponins in acute pulmonary embolism. Circulation 2007;116:427-33.
13 Qanadli SD, El Hajiam M, Vieillard-Baron A, et al. New CT index to quantify arterial obstruction in pulmonary embolism: comparison with angiographic index and echocardiography. AJR Am J Roentgenol 2001;176:1415-20.

14 Sharifi M, Bay C, Skrocki L, et al. Moderate pulmonary embolism treated with thrombolysis (from the "MOPETT" Trial). Am J Cardiol 2013;111:273-7.

15 Wang C, Zhai Z, Yang Y, et al. Efficacy and safety of low dose recombinant tissue-type plasminogen activator for the treatment of acute pulmonary thromboembolism: a randomized, multicenter, controlled trial. Chest 2010;137:254-62.

16 Zhang L-Y, Gao B-A, Jin Z, et al. Clinical efficacy of low dose recombinant tissue-type plasminogen activator for the treatment of acute intermediate-risk pulmonary embolism. Saudi Med J 2018;39:1090-5.

17 Goldhaber SZ, Come PC, Lee RT, et al. Alteplase versus heparin in acute pulmonary embolism: randomised trial assessing right-ventricular function and pulmonary perfusion. Lancet 1993;341:507-11.

18 Kline JA, Nordenholz KE, Courtney DM, et al. Treatment of submassive pulmonary embolism with tenecteplase or placebo: cardiopulmonary outcomes at 3 months: multicenter double-blind, placebo-controlled randomized trial. J Thromb Haemost 2014;12:459-68.

19 Becattini C, Agnelli G, Salvi A, et al. Bolus tenecteplase for right ventricle dysfunction in hemodynamically stable patients with pulmonary embolism. Thromb Res 2010;125:e82-6.

20 Daniels LB, Parker JA, Patel SR, et al. Relation of duration of symptoms with response to thrombolytic therapy in pulmonary embolism. Am J Cardiol 1997;80:184-8.

21 Kucher N, Rossi E, De Rosa M, et al. Prognostic role of echocardiography among patients with acute pulmonary embolism and a systolic arterial pressure of $90 \mathrm{MM} \mathrm{Hg}$ or higher. Arch Intern Med 2005;165:1777-81.

22 Sanchez O, Trinquart L, Caille V, et al. Prognostic factors for pulmonary embolism: the PreP study, a prospective multicenter cohort study. Am J Respir Crit Care Med 2010;181:168-73.

23 Konstantinides S, Geibel A, Heusel G, et al. Heparin plus alteplase compared with heparin alone in patients with submassive pulmonary embolism. $N$ Engl J Med 2002;347:1143-50.

24 Sinha SK, Sachan M, Goel A, et al. Efficacy and safety of thrombolytic therapy in acute submassive pulmonary embolism: follow-up study. J Clin Med Res 2017;9:163-9.

25 Canan Hasanoğlu H, Hezer H, Karalezli A, et al. Half-dose recombinant tissue plasminogen activator treatment in venous thromboembolism. J Investig Med 2014;62:71-7.

26 Brandt K, McGinn K, Quedado J. Low-dose systemic alteplase (tPA) for the treatment of pulmonary embolism. Ann Pharmacother 2015:49:818-24.

27 Rester BT, Warnock JL, Patel PB, et al. Lysis of a left ventricular thrombus with recombinant tissue plasminogen activator. Chest 2001;120:681-3.

28 Zhang Z, Zhai Z-guo, Liang L-rong, et al. Lower dosage of recombinant tissue-type plasminogen activator (rt-PA) in the treatment of acute pulmonary embolism: a systematic review and meta-analysis. Thromb Res 2014;133:357-63.

29 Nakamura S, Takano H, Kubota Y, et al. Impact of the efficacy of thrombolytic therapy on the mortality of patients with acute submassive pulmonary embolism: a meta-analysis. J Thromb Haemost 2014;12:1086-95. 